\title{
Review of Analytical Results from the Proposed Agent Disposal Facility Site, Aberdeen Proving Ground
}

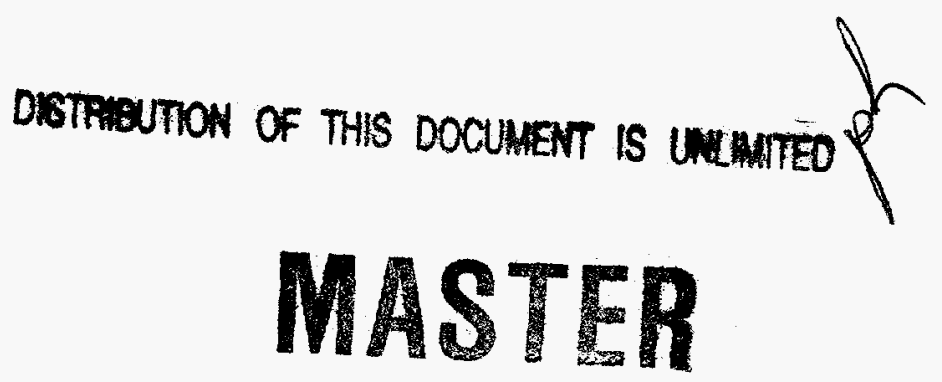

Energy Systems Division

Argonne National Laboratory

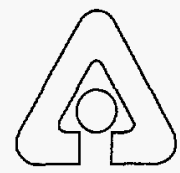

Operated by The University of Chicago, under Contract W-31-109-Eng-38, for the

United States Department of Energy 


\section{Argonne National Laboratory}

Argonne National Laboratory, with facilities in the states of Illinois and Idaho, is owned by the United States Government, and operated by the University of Chicago under the provisions of a contract with the Department of Energy.

This technical memo is a product of Argonne's Energy Systems (ES) Division. For information on the division's scientific and engineering activities, contact:

Director, Energy Systems Division

Argonne National Laboratory

Argonne, Illinois 60439-4815

Telephone (630) 252-3724

Presented in this technical memo are preliminary results of ongoing work or work that is more limited in scope and depth than that described in formal reports issued by the ES Division.

Publishing support services were provided by Argonne's Information and Publishing Division (for more information, see IPD's home page: http://www.jpd.anl.gov/

\section{Disclaimer}

This report was prepared as an account of work sponsored by an agency of the United States Government. Neither the United States Government nor any agency thereof, nor any of their employees, makes any warranty, express or implied, or assumes any legal liability or responsibility for the accuracy, completeness, or usefulness of any information, apparatus, product, or process disclosed, or represents that its use would not infringe privately owned rights. Reference herein to any specific commercial product, process, or senvice by trade name, trademark, manufacturer, or otherwise, does not necessarily constitute or imply its endorsement, recommendation, or favoring by the United States Government or any agency thereof. The views and opinions of authors expressed herein do not necessarily state or reflect those of the United States Government or any agency thereof.

Reproduced directly from the best available copy.

Available to DOE and DOE contractors from the Office of Scientific and Technical Information, P.O. Box 62, Oak Ridge, TN 37831; prices avallable from (423) $576-8401$.

Available to the public from the National Technical Information Service, U.S. Department of Commerce, 5285 Port Royal Road, Springfield, VA 22161. 


\section{DISCLAIMER}

Portions of this document may be illegible electronic image products. Images are produced from the best available original document. 


\title{
Review of Analytical Results from the Proposed Agent Disposal Facility Site, Aberdeen Proving Ground
}

\author{
K.L. Brubaker, L.L. Reed, S.W. Myers, ${ }^{*}$ L.T. Shepard, and T.G. Sydelko
}

The Center for Environmental Restoration Systems, Energy Systems Division, Argonne National Laboratory, 9700 South Cass Avenue, Argonne, Illinois 60439

Work sponsored by United States Department of Defense, U.S. Army Program Manager for Chemical Demilitarization, Aberdeen Proving Ground, Maryland 
全

This report is printed on recycled paper. 


\section{Contents}

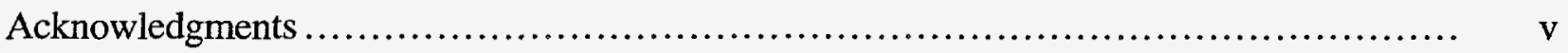

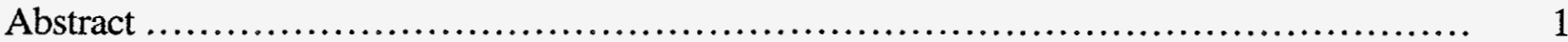

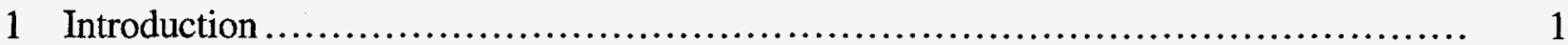

2 Suitability of Analytical Methods .............................................. 4

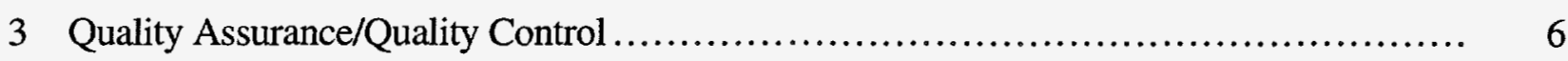

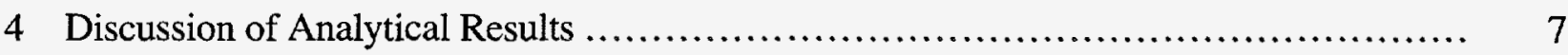

4.1 Organic Analytes................................................................ 7

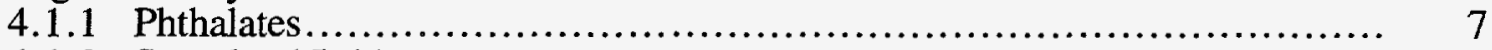

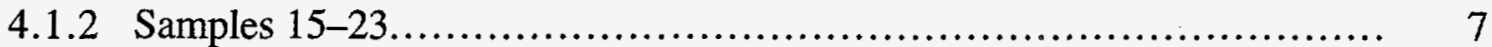

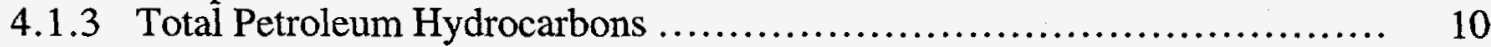

4.1.4 Pesticides ................................................................ 11

4.1 .5 Total Organic Halides ............................................... 11

4.1 .6 Volatile Organics........................................................ 11

4.1.7 Mass-Spectral Library Search Results .................................. 11

4.2 TCLP Analytes........................................................... 13

4.3 Soil Composition Data ........................................................ 17

5 Summary of Findings..................................................... 20

5.1 Analytical Method Suitability ............................................. 20

5.2 Quality Assurance/Quality Control ............................................. 21

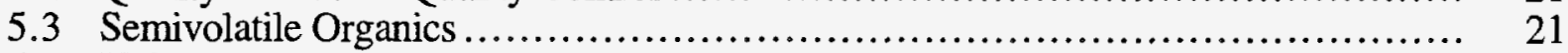

5.4 Volatile Organics.................................................................. 21

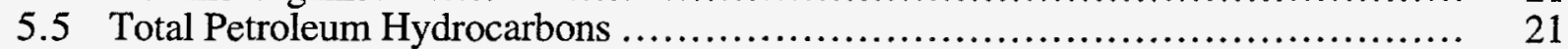

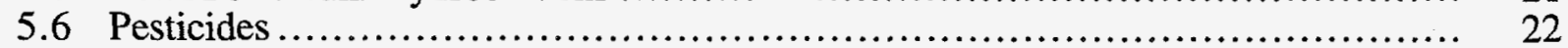

5.7 Total Organic Halides .............................................................. 22

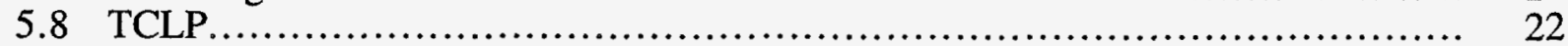

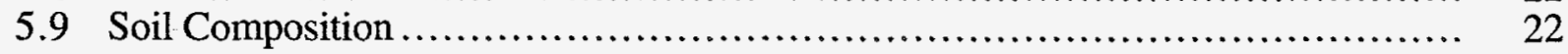

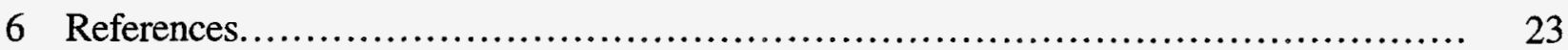

Figure

1 Site Map of the Proposed Chemical Agent Disposal Facility, Aberdeen Proving Ground, Maryland.... 


\section{Tables}

1 Sampling Dates for Composite Soil Samples ................................. 2

2 Summary of Analytical Methods Used ........................................ 5

3 Data Summary - Organics ................................................ 8

4 Data Summary - Results of Method 8260 Volatile Organic Library Search............ 12

5 Data Summary - Results of Method 8270 Semivolatile Organic Library Search......... 14

6 Data Summary - TCLP Metals........................................... 16

7 Data Summary — Soil Composition......................................... 18

8 Highest Concentrations of Identified Organic Contaminants....................... 20 


\title{
Review of Analytical Results from the Proposed Agent Disposal Facility Site, Aberdeen Proving Ground
}

\author{
by \\ K.L. Brubaker, L.L. Reed, S.W. Myers, ${ }^{*}$ L.T. Shepard, and T.G. Sydelko
}

\begin{abstract}
Argonne National Laboratory reviewed the analytical results from 57 composite soil samples collected in the Bush River area of Aberdeen Proving Ground, Maryland. A suite of 16 analytical tests involving 11 different SW-846 methods was used to detect a wide range of organic and inorganic contaminants. One method (BTEX) was considered redundant, and two "single-number" methods (TPH and TOX) were found to lack the required specificity to yield unambiguous results, especially in a preliminary investigation. Volatile analytes detected at the site include 1,1,2,2-tetrachloroethane, trichloroethylene, and tetrachloroethylene, all of which probably represent residual site contamination from past activities. Other volatile analytes detected include toluene, tridecane, methylene chloride, and trichlorofluoromethane. These compounds are probably not associated with site contamination but likely represent cross-contamination or, in the case of tridecane, a naturally occurring material. Semivolatile analytes detected include three different phthalates and low part-per-billion amounts of the pesticide DDT and its degradation product DDE. The pesticide could represent residual site contamination from past activities, and the phthalates are likely due, in part, to crosscontamination during sample handling. A number of high-molecular-weight hydrocarbons and hydrocarbon derivatives were detected and were probably naturally occurring compounds.
\end{abstract}

\section{Introduction}

The primary objective of this review was to compile detailed results from laboratory analyses of composite soil samples taken from the proposed site of the chemical agent disposal facility in the Bush River area of Aberdeen Proving Ground (APG), Maryland. The APG Directorate of Safety, Health, and Environment, Hazardous Waste Branch, will use the results to determine the nature and extent of any necessary remediation at the site of the proposed facility. Additional objectives were to examine the suitability of the analytical methods employed and review the overall quality assurance/quality control results reported by the analytical laboratory.

\footnotetext{
* S.W. Myers is affiliated with Hydro-Terra, Inc., Columbia, Maryland.
} 
Argonne National Laboratory (ANL) collected 57 composite soil samples between January and July 1997, as shown in Table 1. Also shown in Table 1 are the dates on which the samples were received by the analytical laboratory, Ana-Lab Corporation. A map of the site of the proposed facility showing the locations of all 57 samples is provided in Figure 1.

TABLE 1 Sampling Dates for Composite Soil Samples

\begin{tabular}{llll}
\hline Phase & Sample Numbers & Dates Collected & Date Received \\
\hline IV & $1-12$ & $01 / 07-01 / 08 / 97$ & $01 / 10 / 97$ \\
V & $13-23$ & $03 / 03-03 / 04 / 97$ & $03 / 07 / 97$ \\
VI & $24-36$ & $03 / 31-04 / 02 / 97$ & $04 / 04 / 97$ \\
VII & $37-42$ & $05 / 12 / 97$ & $05 / 16 / 97$ \\
VIII & $43-45,53,54,57$ & $06 / 09-06 / 11 / 97$ & $06 / 13 / 97$ \\
IX & $46-52,55,56$ & $07 / 14-07 / 16 / 97$ & $07 / 18 / 97$ \\
\hline
\end{tabular}

a Date received by Ana-Lab Corp. 


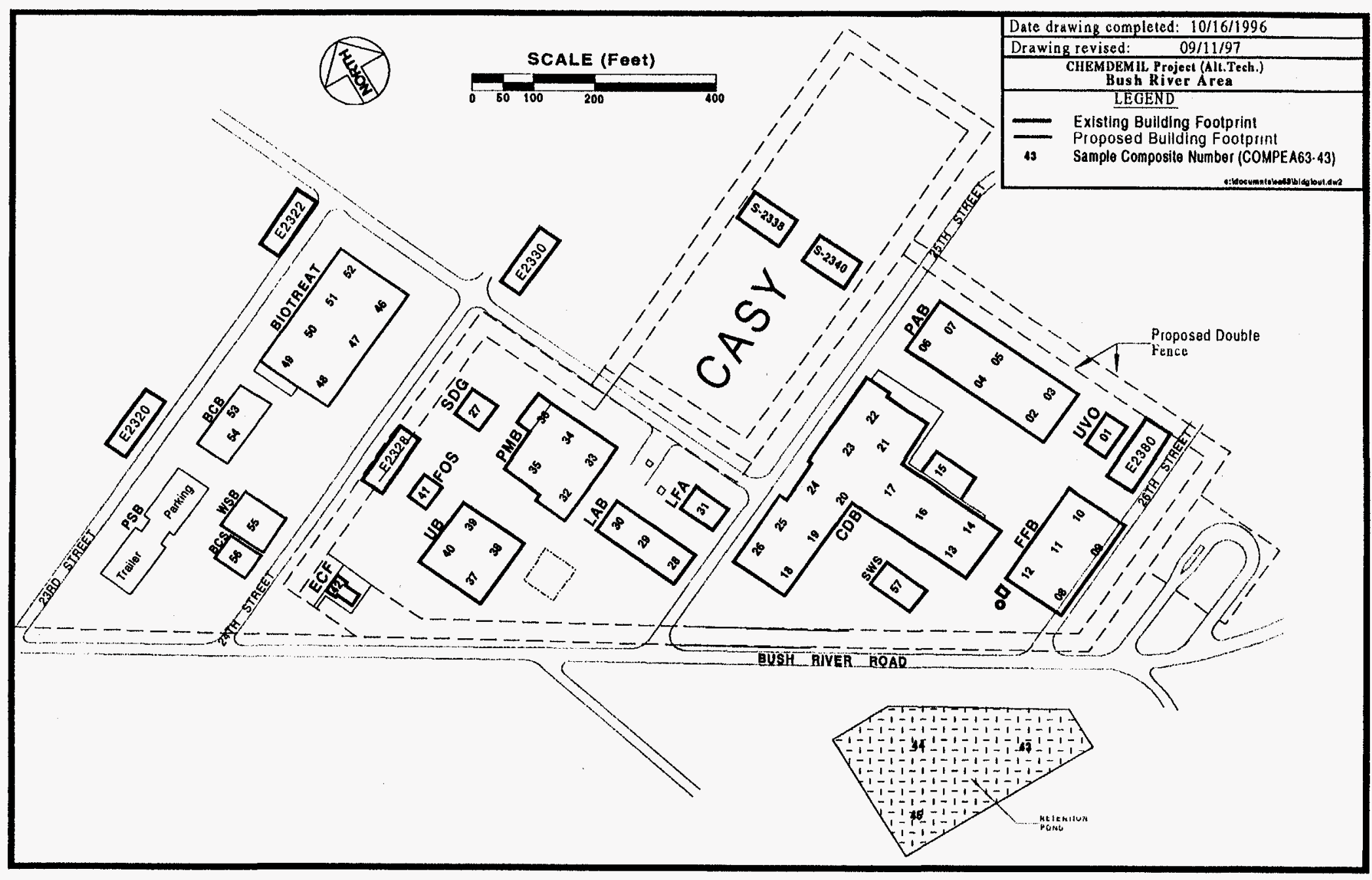

FIGURE 1 Site Map of the Proposed Chemical Agent Disposal Facility, Aberdeen Proving Ground, Maryland 


\section{Suitability of Analytical Methods}

Table 2 lists the analytical methods used for the composite samples of interest. All methods are taken from the U.S. Environmental Protection Agency (EPA) compendium, SW-846 (U.S. Environmental Protection Agency 1986), except the method used to determine solids (American Public Health Association 1992). All the methods listed in the table are appropriate for use with soil samples, except Method 9020 (Total Organic Halides, or TOX). According to the description of the method (U.S. Environmental Protection Agency 1986), Method 9020 is applicable for analyzing drinking water and for groundwater samples, but it is not appropriate for measuring TOX adsorbed onto undissolved solids. In addition, this method is not specific to halogenated compounds, because any organics (such as aromatic hydrocarbons) that will be detected by a photoionization detector will also be detected by this method.

The BETX method (Method 8021), while applicable to soil samples, is redundant for the samples of interest here because Method 8260 can be used to determine BETX hydrocarbons down to considerably lower concentrations.

The two methods used for general hydrocarbon detection - Method 418.1 (Total Recoverable Petroleum Hydrocarbons, or TPH) and Method 8015 (modified) (Nonhalogenated Volatile Organics by Gas Chromatography, also called TPH by some authorities) - do not provide compound-specific concentration values and are not necessarily specific to the hydrocarbons of concern (e.g., petroleum hydrocarbons). Method 418.1 detects compounds through the infrared absorption due to the carbon-hydrogen bonds found in nearly all classes of organic matter; virtually any organic substance that will dissolve in the fluorocarbon extraction solvent used will be detected if present in large enough quantities. Method 8015 (modified) is somewhat more specific in that only those hydrocarbons that can be either volatilized or extracted and analyzed by using gas chromatography will be found (typically, organics having carbon numbers in the range $\mathrm{C}_{6}$ to $\mathrm{C}_{26}$ ). In the modified method, both volatile and extractable hydrocarbons are determined and reported separately. Both methods are designed for use with petroleum hydrocarbons. Method 8015 (modified) is more suitable for exploratory work in which the presence or absence of petroleum hydrocarbons is to be determined, while Method 418.1 is more suitable for use in situations where the presence of contamination has already been established at sufficiently high levels. Because neither method provides compound-specific concentrations, the detection of hydrocarbons with either method does not necessarily imply the existence of a threat to human health or the environment. 
TABLE 2 Summary of Analytical Methods Used

\begin{tabular}{|c|c|c|c|}
\hline Analyte Class & Method & Number & Method Name \\
\hline TCLP Metals & SW-846 & 6010 & Inductively Coupled Plasma-Atomic Emission Spectroscopy \\
\hline TCLP Mercury & SW-846 & 7470 & Mercury in Liquid Waste (Manual Cold-Vapor Technique) \\
\hline TCLP Pesticides & SW-846 & 8080 & $\begin{array}{l}\text { Organochlorine Pesticides and Polychlorinated Biphenyls by } \\
\text { Gas Chromatography }\end{array}$ \\
\hline TCLP Herbicides & SW-846 & 8150 & Chlorinated Herbicides by Gas Chromatography \\
\hline TCLP VOA & SW-846 & 8260 & $\begin{array}{l}\text { Volatile Organic Compounds by Gas Chromatography/Mass } \\
\text { Spectrometry (GC/MS): Capillary Column Technique }\end{array}$ \\
\hline TCLP SVOA & SW-846 & 8270 & $\begin{array}{l}\text { Semivolatile Organic Compounds by Gas } \\
\text { Chromatography/Mass Spectrometry (GC/MS): Capillary } \\
\text { Column Technique }\end{array}$ \\
\hline BTEX & SW-846 & 8021 & $\begin{array}{l}\text { Halogenated Volatiles by Gas Chromatography Using } \\
\text { Photoionization and Electrolytic Conductivity Detectors in } \\
\text { Series: Capillary Column Technique }\end{array}$ \\
\hline PCBs & SW-846 & 8081 & $\begin{array}{l}\text { Organochlorine Pesticides and PCBs as Arochlors by Gas } \\
\text { Chromatography: Capillary Column Technique }\end{array}$ \\
\hline Pesticides & SW-846 & 8081 & see above \\
\hline VOA & SW-846 & 8260 & see above \\
\hline SVOA & SW-846 & 8270 & see above \\
\hline TPH & SW-846 & 418.1 & Total Recoverable Petroleum Hydrocarbons \\
\hline Hydrocarbons & $\begin{array}{l}\text { SW-846 } \\
\text { (Modifiec }\end{array}$ & 8015 & Nonhalogenated Volatile Organics by Gas Chromatography \\
\hline Metals & SW-846 & 6010 & see above \\
\hline TOX & SW-846 & $9020 \mathrm{~A}$ & Total Organic Halides (TOX) \\
\hline Solids & APHA 25 & $540 G$ & $\begin{array}{l}\text { Total, Fixed, and Volatile Solids in Solid and Semisolid } \\
\text { Samples }\end{array}$ \\
\hline
\end{tabular}




\section{Quality Assurance/Quality Control}

The quality control $(\mathrm{QC})$ results provided in support of the analytical data were examined for completeness and compliance with SW-846 requirements. Twelve samples, two from each batch of samples sent to the laboratory, were selected at random for detailed examination; this number corresponds to $8.3 \%$ of the total number of samples. The QC results for the remaining samples were also examined, but in less detail.

For each sample examined in detail, it was possible to find QC results that were out of compliance with requirements. However, the percentage of such results was judged to be less than $5 \%$ of the total number of QC measurements, and with one exception, no pervasive or systematic problems were found with any of the QC data. The exception occurs for PCBs: no PCB-specific QC data (matrix spikes, blanks, check standards) were provided for samples 43-57, although adequate $\mathrm{QC}$ data were provided for chlorinated pesticides. $\mathrm{PCBs}$ and chlorinated pesticides were determined by using the same method (SW-846 8081).

On the basis of this examination of the QC results, the quality of the analytical data is considered adequate for their intended use. 


\section{Discussion of Analytical Results}

\subsection{Organic Analytes}

The results from the analyses for various organic analytes are shown in Table 3. Several points can be made about these data; these points will be discussed in turn.

\subsubsection{Phthalates}

Low (sub-ppm) levels of phthalates, primarily di-n-butyl phthalate, appear to be present in most samples collected from the proposed locations of the CDB, PAB, FFB, and UVO buildings, all of which are on the southeast side of the site. Many of these levels are only slightly above the Estimated Quantitation Limit (EQL), which varied from 330 to $410 \mu \mathrm{g} / \mathrm{kg}$ over the course of the sampling program. However, phthalates are also common laboratory contamination artifacts because they are used as plasticizers in rubber bulbs and other similar equipment used in analytical laboratories. An unambiguous determination of the source of the phthalates cannot be made because no field QC samples, specifically field and trip blanks, were included in the sampling plan. Laboratory contamination would have been indicated if contaminants were reported for such samples.

Internal evidence in Table 3 suggests that the phthalates are, indeed, laboratorycontamination artifacts. Samples 1-12 and 13-23 were collected and analyzed in January and early March, respectively (sampling phases IV and V), while samples 24-26 and 57, which are also located in the suspect area, were collected and analyzed at later dates, in sampling phases VI and VIII. The fact that no phthalates were found in these later samples suggests that the analytical laboratory found and corrected a source of phthalate contamination in its own operations between the dates of sampling phases V and VI, and that the apparent presence of phthalates in these samples is due to this contamination.

\subsubsection{Samples $15-23$}

The results shown in Table 3 for samples 15-23 indicate a somewhat higher level of organic contamination than elsewhere; therefore, the area covered by these samples could have been used for some activity in the past. This possibility is supported by the fact that the area is open and covered by crushed rock and gravel rather than by vegetation. The highest phthalate concentrations are found here (in samples 18, 19, and 21), and this finding may indicate that phthalates are present in this area in addition to the possible laboratory contamination discussed above. The only samples in which chlorinated hydrocarbon solvents were found are in this area (samples 15, 20, 22, and 23). Two of the three chlorinated hydrocarbons (trichloroethylene and 
TABLE 3 Data Summary - Organics ${ }^{a}$

\begin{tabular}{|c|c|c|c|c|c|c|c|c|}
\hline \multirow[b]{2}{*}{ Sample } & \multicolumn{7}{|c|}{ Method } & \multirow[b]{2}{*}{$\begin{array}{l}\text { Substances } \\
\text { Detected }\end{array}$} \\
\hline & $\begin{array}{c}8260 \\
\text { VOA } \\
(\mu \mathrm{g} / \mathrm{kg})\end{array}$ & $\begin{array}{c}8270 \\
\text { SVOA } \\
(\mu \mathrm{g} / \mathrm{kg})\end{array}$ & $\begin{array}{c}9020 A \\
\text { TOX } \\
(\mathrm{mg} / \mathrm{kg})\end{array}$ & $\begin{array}{c}8021 \\
\text { BTEX } \\
(\mu \mathrm{g} / \mathrm{kg})\end{array}$ & $\begin{array}{c}8081 \\
\mathrm{PCB} \\
(\mu \mathrm{g} / \mathrm{kg})\end{array}$ & $\begin{array}{c}8081 \\
\text { Pesticides } \\
(\mu \mathrm{g} / \mathrm{kg})\end{array}$ & $\begin{array}{c}418.1 \\
\mathrm{TPH} \\
(\mathrm{mg} / \mathrm{kg})\end{array}$ & \\
\hline 1 & ND & 920 & 12 & ND & ND & $\cdots$ & ND & Di-n-butylphthalate \\
\hline 2 & ND & 710 & 12 & ND & ND & ---- & ND & Di-n-butylphthalate \\
\hline 3 & ND & 910 & 12 & ND & ND & .... & 27 & Di-n-butylphthalate \\
\hline 4 & ND & 510 & 8.2 & ND & ND & $\ldots$ & 12 & Di-n-butylphthalate \\
\hline 5 & ND & 660 & ND & ND & ND & --- & 12 & Di-n-butylphthalate \\
\hline 6 & ND & 600 & 23 & ND & ND & $\cdots$ & ND & Di-n-butylphthalate \\
\hline 7 & ND & 550 & 11 & ND & ND & $\ldots$ & ND & Di-n-butylphthalate \\
\hline 8 & ND & 360 & 10 & ND & ND & $\cdots$ & ND & Di-n-butylphthalate \\
\hline 9 & ND & 450 & 14 & ND & ND & ---- & 15 & Di-n-butylphthalate \\
\hline 10 & ND & 400 & 17 & ND & ND & --- & ND & Di-n-butylphthalate \\
\hline 11 & ND & 370 & ND & ND & ND & $\ldots$ & ND & Di-n-butylphthalate \\
\hline 12 & ND & ND & 8.2 & ND & ND & $\cdots$ & ND & \\
\hline 13 & ND & 1600 & 25 & ND & ND & $-\cdots$ & ND & Di-n-butylphthalate \\
\hline 14 & ND & 1600 & 20 & ND & ND & ---- & 25 & Di-n-butylphthalate \\
\hline 15 & $\begin{array}{r}1100 \\
29\end{array}$ & & 6.3 & ND & ND & --- & ND & $\begin{array}{l}\text { 1,1,2,2-tetrachloroethane } \\
\text { Trichloroethylene }\end{array}$ \\
\hline & & 1600 & & & & & & Di-n-butylphthalate \\
\hline 16 & ND & 1200 & 14 & ND & ND & --- & 15 & Di-n-butylphthalate \\
\hline 17 & ND & 1200 & 5 & ND & ND & --- & 11 & Di-n-butylphthalate \\
\hline 18 & ND & $\begin{array}{r}2000 \\
630\end{array}$ & 9.5 & ND & ND & --- & 17 & $\begin{array}{l}\text { Di-n-butylphthalate } \\
\text { Diethyl phthalate }\end{array}$ \\
\hline 19 & ND & $\begin{array}{r}660 \\
1100 \\
3200\end{array}$ & 7.7 & ND & ND & ---- & ND & $\begin{array}{l}\text { Benzyl butyl phthalate } \\
\text { Di-n-butylphthalate } \\
\text { Diethyl phthalate }\end{array}$ \\
\hline 20 & $\begin{array}{r}11 \\
110\end{array}$ & & 10 & ND & ND & -... & 11 & $\begin{array}{l}\text { 1,1,2,2-tetrachloroethane } \\
\text { Trichloroethylene }\end{array}$ \\
\hline 21 & ND & $\begin{array}{l}1900 \\
2000\end{array}$ & 6.6 & ND & ND & ---- & 17 & $\begin{array}{l}\text { Di-n-butylphthalate } \\
\text { Di-n-butylphthalate }\end{array}$ \\
\hline 22 & 8.5 & 1600 & 8.5 & ND & ND & --- & 17 & $\begin{array}{l}\text { Tetrachloroethylene } \\
\text { Di-n-butylphthalate }\end{array}$ \\
\hline 23 & 23 & $\begin{array}{l}1600 \\
1700\end{array}$ & 6.8 & ND & ND & ---- & 15 & $\begin{array}{l}\text { Tetrachloroethylene } \\
\text { Di-n-butylphthalate } \\
\text { Diethyl phthalate }\end{array}$ \\
\hline 24 & ND & ND & ND & ND & ND & ...- & ND & \\
\hline 25 & ND & ND & ND & ND & ND & --.- & ND & \\
\hline 26 & ND & ND & ND & ND & ND & .... & ND & \\
\hline 27 & ND & ND & ND & ND & ND & ---- & ND & \\
\hline 28 & ND & ND & ND & ND & ND & $\ldots$ & ND & \\
\hline 29 & ND & ND & ND & ND & ND & $\ldots$ & ND & \\
\hline 30 & ND & ND & ND & ND & ND & -..- & ND & \\
\hline 31 & ND & ND & 6.4 & ND & ND & --- & ND & \\
\hline 32 & ND & 360 & ND & ND & ND & $\ldots$ & ND & Di-n-butylphthalate \\
\hline 33 & ND & ND & ND & ND & ND & --- & ND & \\
\hline 34 & ND & 580 & ND & ND & ND & $\cdots$ & ND & Di-n-butylphthalate \\
\hline
\end{tabular}


TABLE 3 (Cont.)

\begin{tabular}{|c|c|c|c|c|c|c|c|c|}
\hline \multirow[b]{2}{*}{ Sample } & \multicolumn{7}{|c|}{ Method } & \multirow[b]{2}{*}{$\begin{array}{l}\text { Substances } \\
\text { Detected }\end{array}$} \\
\hline & $\begin{array}{c}8260 \\
\text { VOA } \\
(\mu \mathrm{g} / \mathrm{kg})\end{array}$ & $\begin{array}{c}8270 \\
\text { SVOA } \\
(\mu \mathrm{g} / \mathrm{kg})\end{array}$ & $\begin{array}{c}9020 A \\
\text { TOX } \\
(\mathrm{mg} / \mathrm{kg})\end{array}$ & $\begin{array}{c}8021 \\
\text { BTEX } \\
(\mu \mathrm{g} / \mathrm{kg})\end{array}$ & $\begin{array}{c}8081 \\
\mathrm{PCB} \\
(\mu \mathrm{g} / \mathrm{kg})\end{array}$ & $\begin{array}{c}8081 \\
\text { Pesticides } \\
(\mu \mathrm{g} / \mathrm{kg})\end{array}$ & $\begin{array}{c}418.1 \\
\mathrm{TPH} \\
(\mathrm{mg} / \mathrm{kg})\end{array}$ & \\
\hline \multirow[t]{2}{*}{35} & 5.5 & & ND & ND & ND & ---- & ND & Trichlorofluoromethane \\
\hline & & 540 & & & & & & Di-n-butylphthalate \\
\hline 36 & ND & ND & ND & ND & ND & --- & ND & \\
\hline 37 & ND & ND & 13.3 & ND & ND & --- & (dry wt) 59 & \\
\hline 38 & 6.7 & ND & 11.1 & ND & ND & --- & (dry wt) 79 & Trichlorofluoromethane \\
\hline 39 & ND & ND & 10.0 & ND & ND & --- & ND & \\
\hline 40 & 6.8 & ND & 18.5 & ND & ND & $\ldots$ & ND & Trichlorofluoromethane \\
\hline 41 & ND & ND & 17.5 & ND & ND & --- & ND & \\
\hline 42 & 7.2 & ND & 11.2 & ND & ND & ---- & ND & Trichlorofluoromethane \\
\hline 43 & ND & ND & 7 & ND & ND & ND & 17 & \\
\hline 44 & ND & ND & ND & ND & ND & ND & 20 & \\
\hline 45 & ND & ND & ND & ND & ND & ND & 11 & \\
\hline \multirow[t]{2}{*}{46} & ND & ND & 8.2 & ND & ND & 5.29 & $22^{b}, N^{c}$ & 4,4'-DDE \\
\hline & & & & & & 7.03 & & $4,4^{\prime}$-DDT \\
\hline \multirow[t]{2}{*}{47} & ND & ND & 12 & ND & ND & 11.1 & $31^{b}, N D^{c}$ & $4,4^{\prime}-\mathrm{DDE}$ \\
\hline & & & & & & 12.8 & & 4,4'-DDT \\
\hline \multirow[t]{3}{*}{48} & 5.8 & ND & $-\cdots-$ & ND & ND & & $33^{b}, N^{c}$ & Toluene \\
\hline & & & & & & 15.8 & & $4,4^{\prime}-\mathrm{DDE}$ \\
\hline & & & & & & 21.5 & & 4,4'-DDT \\
\hline \multirow[t]{2}{*}{49} & ND & ND & $\cdots$ & ND & ND & 10.8 & $26^{b}, N^{c}$ & 4,4'-DDE \\
\hline & & & & & & 12 & & 4,4'-DDT \\
\hline \multirow[t]{2}{*}{50} & ND & ND & ---- & ND & ND & 3.05 & $18^{b}, N^{c}$ & $4,4^{\prime}$-DDE \\
\hline & & & & & & 3.67 & & 4,4'-DDT \\
\hline \multirow[t]{3}{*}{51} & 6.5 & ND & -.- & ND & ND & & $24^{b}, N D^{c}$ & Toluene \\
\hline & & & & & & 10.5 & & 4,4'-DDE \\
\hline & & & & & & 9.13 & & 4,4'-DDT \\
\hline \multirow[t]{2}{*}{52} & ND & ND & ---- & ND & ND & 8.48 & $43^{b}, N D^{c}$ & 4,4'-DDE \\
\hline & & & & & & 5.74 & & 4,4'-DDT \\
\hline 53 & ND & ND & ND & ND & ND & ND & 18 & \\
\hline 54 & 10 & ND & ND & ND & ND & ND & 14 & Methylene chloride \\
\hline \multirow[t]{4}{*}{55} & 5.6 & ND & $-\cdots$ & ND & ND & & $38^{b}, N^{c}$ & Toluene \\
\hline & 9.1 & & & & & & & Trichlorofluoromethane \\
\hline & & & & & & 25.4 & & 4,4'-DDE \\
\hline & & & & & & 13.6 & & $4,4^{\prime}-\mathrm{DDT}$ \\
\hline 56 & --- & $\ldots$ & $-\ldots$ & ND & -..- & -.- & $48^{b}, N D^{c}$ & \\
\hline 57 & ND & ND & ND & ND & ND & ND & ND & \\
\hline
\end{tabular}

a The highest reported concentration for each identified compound is shown in boldface numerals.

b Value obtained by using Method 418.1.

c Value obtained by using Method 8015 
tetrachloroethylene) found in these samples are also on the TCLP/VOA analyte list; however, these substances were not detected in the TCLP leachate from these samples. Results from the independent worker-safety-related analyses confirm the detection of all the chlorinated hydrocarbons found in these samples. In each case, the same analytes were detected in one or more of the subsamples making up the composite sample. A positive detection for Total Organic Halides (TOX) was reported for all these samples, and a positive detection for Total "Petroleum" Hydrocarbons (TPH) was reported for all but two of these samples.

\subsubsection{Total Petroleum Hydrocarbons}

The TPH data (Method 418.1) seem to indicate at least two sources of hydrocarbons. As just described, positive TPH results were reported for all but two of samples 15-23. The possible presence of petroleum hydrocarbons in these samples is consistent with other data that suggest that this area has been used in the past.

The only other areas for which TPH results are consistently positive are (1) the retention pond (samples 43-45) and (2) that area covered by the proposed locations of the BIOTREAT, $\mathrm{BCB}, \mathrm{BCS}$, and WSB buildings on the northwest side of the site (samples 46-56). These areas are currently covered by woods and shrubbery, and the positive TPH results are probably due to naturally occurring hydrocarbons produced by plant metabolism or the decay of plant matter rather than to the existence of hydrocarbon contamination from some earlier human activity. The TPH results for samples 3, 4, and 5 may also be positive because they were collected from wooded locations. The existence of a wide variety of naturally occurring organic substances in soils, including many that also occur in petroleum hydrocarbons, is well-documented (Dragun and Barkach 1989). Several compounds chemically similar to these were found in the SVOA massspectral library search discussed below. Although the correlation in the data of Table 2 between a high level of vegetative cover and a positive TPH result is not perfect, it is good enough to strongly suggest that a positive TPH result does not necessarily indicate the presence of contamination. The nonspecific nature of this analysis can lead to misleading results without other corroborating evidence of petroleum hydrocarbon contamination (Gustafson undated).

Two TPH results using Method 418.1 were reported on a dry-weight basis instead of the wet-weight basis used for the rest of the samples. These two samples, 37 and 38 , also showed the highest TPH values; converted to a wet-weight basis, they are 49 and $64 \mathrm{mg} / \mathrm{kg}$, respectively. Both samples came from a wooded area.

An analysis for hydrocarbons using Method 8015 (modified) was run for samples 46-52, 55 , and 56 (sampling phase IX), in addition to TPH by Method 418.1. No positive hydrocarbon detections were reported. As described in Section 2, Method 8015 (modified) is more specific to petroleum hydrocarbons than is Method 418.1, although it is not clear why Method 8015 (modified) did not yield a single positive result since it should have detected many of the same naturally occurring hydrocarbons that Method 418.1 detects. A possible explanation is that many of the naturally occurring substances detected by Method 418.1 may not be amenable to analysis 
by the standard gas-chromatographic methods, columns, and temperatures used in Method 8015 (modified).

\subsubsection{Pesticides}

The pesticides 4,4'-DDE and 4,4'-DDT were found at low part-per-billion levels in samples 46-52 and 55. These samples cover the proposed locations of the BIOTREAT, BCS, and WSB buildings. The spatial distribution of the pesticide residue is rather spotty, because pesticides were not detected in (1) samples 53 and 54 (the BCB building location), (2) samples 43-45 (the retention pond), or (3) sample 57 (the SWS building location). Earlier samples were not analyzed for pesticides.

\subsubsection{Total Organic Halides}

The TOX data are difficult to interpret because the analytical method is not necessarily specific for halogenated substances and does not yield compound-specific concentration values. A positive TOX result was reported in all but two samples out of the first 23 taken. In addition, samples 37-42 (the UB, FOS, and ECF building locations) also tested positive for TOX, as did four other samples at scattered locations (numbers $31,43,46$, and 47 ).

\subsubsection{Volatile Organics}

Very low levels of toluene, methylene chloride, and trichlorofluoromethane were detected in several samples. The toluene results (samples 48, 51, and 55) may indicate the presence of toluene in the samples, but the methylene chloride result (10 ppb in sample 54) and the trichlorofluoromethane results (below $10 \mathrm{ppb}$ in samples 35, 38, 40, 42, and 55) are almost certainly laboratory contamination artifacts.

\subsubsection{Mass-Spectral Library Search Results}

The identity of a compound eluting in a GC/MS analysis is determined by comparing its mass spectrum with those contained in a library of mass spectra of known compounds. The quality of a match is indicated in the analytical report by the "Qual" parameter, which ranges from 0 to 100 , with 100 representing a perfect match. High values of Qual (generally greater than 90 ) indicate a high probability of a correct compound identification. 
TABLE 4 Data Summary - Results of Method 8260 Volatile Organic Library Searcha

\begin{tabular}{|c|c|c|c|c|c|c|c|c|c|c|c|c|c|c|c|c|c|c|}
\hline Sample & Compound & $R T^{c}$ & Conc $^{d}$ & $C p d^{b}$ & $R T^{c}$ & Conc $^{d}$ & Compound & $R T^{c}$ & Conc $^{d}$ & $C p d^{b}$ & $\mathrm{RT}^{\mathrm{C}}$ & Conc $^{d}$ & $C p d^{b}$ & $\mathrm{RT}^{\mathrm{c}}$ & Conc $^{d}$ & $C p d^{b}$ & $\mathrm{RT}^{\mathrm{c}}$ & Conc $^{d}$ \\
\hline $1-5$ & ND & & & & & & & & & & & & & & & & & \\
\hline 6 & Unk & 4.44 & 7 & Unk & 4.52 & 7 & Tridecane & 15.16 & 11 & & & & Unk & 15.57 & 16 & Unk & 16.91 & 7 \\
\hline $7-9$ & ND & & & & & & & & & & & & & & & & & \\
\hline 10 & Unk & 8.12 & 6 & & & & & & & & & & & & & & & \\
\hline $11-27$ & ND & & & & & & & & & & & & & & & & & \\
\hline 28 & & & & Unk & 15.57 & 11 & & & & & & & & & & & & \\
\hline $29-36$ & ND & & & & & & & & & & & & & & & & & \\
\hline 37 & Cyclo-4 & 12.70 & 181 & Unk & 15.57 & 287 & & & & & & & Unk & 18.45 & 76 & Unk & 18.46 & 18 \\
\hline 38 & Unk & 12.71 & 109 & Unk & 15.58 & 211 & & & & & & & Unk & 18.46 & 44 & Unk & 18.47 & 10 \\
\hline 39 & Cyclo-4 & 12.71 & 108 & Unk & 15.58 & 129 & Unk & 15.59 & 26 & & & & Unk & 18.46 & 41 & & & \\
\hline 40 & Cyclo-4 & 12.71 & 168 & Unk & 15.58 & 252 & & & & & & & Unk & 18.46 & 64 & Unk & 18.47 & 15 \\
\hline 41 & Cyclo-4 & 12.72 & 105 & Unk & 15.58 & 133 & Unk & 15.59 & 29 & & & & Unk & 18.47 & 43 & Unk & 18.47 & 10 \\
\hline 42 & Cyclo-4 & 12.72 & 251 & Unk & 15.58 & 367 & Unk & 15.59 & 82 & & & & Unk & 18.46 & 123 & Unk & 18.47 & 30 \\
\hline 43 & Unk & 12.71 & 76 & Unk & 15.57 & 84 & Unk & 15.58 & 18 & & & & Unk & 18.45 & 23 & & & \\
\hline 44 & Unk & 12.71 & 250 & Unk & 15.57 & 376 & Unk & 15.58 & 85 & & & & Unk & 18.46 & 73 & Unk & 18.46 & 18 \\
\hline 45 & Cyclo-4 & 12.71 & 69 & Unk & 15.58 & 147 & & & & & & & Unk & 18.46 & 29 & & & \\
\hline 46 & Cyclo-4 & 12.48 & 122 & Unk & 15.33 & 88 & & & & & & & Unk & 18.19 & 19 & & & \\
\hline 47 & & & & Unk & 15.32 & 146 & Unk & 15.33 & 33 & Unk & 15.57 & 14 & Unk & 18.19 & 35 & & & \\
\hline 48 & Cyclo-4 & 12.48 & 357 & Unk & 15.33 & 176 & & & & & & & Unk & 18.19 & 34 & & & \\
\hline 49 & Cyclo-4 & 12.48 & 334 & Unk & 15.33 & 181 & & & & & & & Unk & 18.20 & 46 & & & \\
\hline 50 & Unk & 12.48 & 254 & Unk & 15.33 & 141 & Unk & 15.33 & 31 & Unk & 15.58 & 13 & Unk & 18.19 & 35 & Unk & 18.20 & 9 \\
\hline 51 & Cyclo-4 & 12.48 & 367 & Unk & 15.33 & 211 & & & & & & & Unk & 18.19 & 43 & Unk & 18.20 & 11 \\
\hline 52 & Cyclo-4 & 12.48 & 334 & Unk & 15.33 & 180 & Cyclo-3 & 9.04 & 9 & Unk & 15.58 & 18 & Unk & 18.19 & 36 & Unk & 18.20 & 8 \\
\hline 53 & Cyclo-4 & 12.71 & 227 & Unk & 15.57 & 272 & & & & Unk & 15.58 & 62 & Unk & 18.46 & 49 & Unk & 18.46 & 11 \\
\hline 54 & Unk & 12.71 & 219 & Unk & 15.57 & 261 & Unk & 15.58 & 59 & & & & Unk & 18.46 & 58 & Unk & 18.46 & 14 \\
\hline 55 & Cyclo-4 & 12.48 & 203 & Unk & 15.32 & 138 & Unk & 15.33 & 31 & & & & Unk & 18.19 & 76 & Unk & 18.20 & 19 \\
\hline 56 & No Data & & & & & & & & & & & & & & & & & \\
\hline 57 & Cyclo-4 & 12.71 & 39 & & & & & & & & & & & & & & & \\
\hline
\end{tabular}

a The highest reported concentration for each identified compound is shown in boldface numerals.

b Compound: ND indicates that no library compounds were detected by the search. Unk indicates an unknown compound (the quality of the mass-spectral match was less than $80 \%$ ). Cyclo-3 denotes hexamethyl-cyclotrisiloxane. Cyclo-4 denotes octamethyl-cyclotetrasiloxane.

c RT denotes the retention time in minutes.

${ }^{d}$ Conc denotes the approximate concentration in $\mu \mathrm{g} / \mathrm{kg}$ (parts per billion). 
The results of the volatile organic library search are summarized in Table 4 . The results show that only three compounds were identified with Qual values greater than 80 . The first, tridecane, occurs in sample 6 at an estimated concentration of $11 \mathrm{ppb}$. The second compound, hexamethyl-cyclotrisiloxane, occurs in sample 52 at an estimated concentration of $9 \mathrm{ppb}$. The third compound, octamethyl-cyclotetrasiloxane, occurs in samples $37-55$ and 57 at a maximum concentration of $367 \mathrm{ppb}$. Although some spectral matches for this compound are marked unknown because of a Qual value below 80, the agreement in the GC retention time (the parameter RT in Table 4) clearly suggests that the substance is indeed octamethyl-cyclotetrasiloxane. These two siloxane compounds are routinely found in GC/MS analyses of soil extracts and often is due to chemical breakdown of the GC column's stationary phase. Results from the independent workersafety related analyses confirm the presence of these cyclosiloxanes and indicate the presence of higher molecular weight homologs. The tridecane in sample 6 is the only volatile hydrocarbon found in any of the samples and is probably produced naturally.

Table 5 summarizes the results of the semivolatile organic library search. The five identified peaks with the highest concentrations are found in sample 41 (cyclotetracosane, $3.4 \mathrm{ppm}$ ), sample 55 (1-docosanol acetate, $2.9 \mathrm{ppm}$; 9-octyl-heptadecane, $2.9 \mathrm{ppm}$ ), sample 48 (1-docosanol acetate, $2.7 \mathrm{ppm}$ ), and sample 39 (cyclotetracosane, $2.5 \mathrm{ppm}$ ). These are all high-molecular-weight $\left(\mathrm{C}_{24}-\mathrm{C}_{25}\right)$ hydrocarbons or hydrocarbon derivatives that occur naturally in soil.

Much of the remaining data in Table 5 can be classified on the basis of GC retention times. For example, samples 46-50 all contain a compound eluting at 27.74 min. In each case, the compound is identified by the library search as 1-dotricontanol, a $\mathrm{C}_{32}$ alcohol found in plants. Thus, it appears that the GC peaks identified as a hydrocarbon or as hydrocarbon-related compounds in Table 5 can be traced to naturally occurring substances found in areas covered by woods and shrubbery.

\subsection{TCLP Analytes}

Analyses were done on the samples of interest for TCLP metals, including mercury, TCLP pesticides, TCLP herbicides, TCLP volatile organics, and TCLP semivolatile organics. The only TCLP analyses that resulted in the detection of the analyte were the metals analyses. The result of all other TCLP analyses was nondetection.

Table 6 summarizes the results of the TCLP metals analysis. Blank entries represent nondetections. At the top of the table, the EPA's regulatory limits for the indicated metals are shown. All analytical results were well below the corresponding regulatory limits. 
TABLE 5 Data Summary - Results of Method 8270 Semivolatile Organic Library Searcha

\begin{tabular}{|c|c|c|c|c|c|c|c|c|c|c|c|c|c|c|}
\hline$R T^{b}$ & Conc $^{c}$ & $1 D^{d}$ & $R T^{b}$ & Conc $^{c}$ & $10^{d}$ & $R T^{b}$ & Conc $^{c}$ & $1 D^{d}$ & $R T^{b}$ & Conc $^{\circ}$ & $I D^{d}$ & $R T^{b}$ & Conc $^{c}$ & $1 D^{d}$ \\
\hline \multicolumn{3}{|c|}{ Sample 1} & \multicolumn{3}{|c|}{ Sample 2} & \multicolumn{3}{|c|}{ Sample 3} & \multicolumn{3}{|c|}{ Sample 4} & & & \\
\hline 20.48 & 0.2 & unk & & & & 19.58 & 0.5 & unk & 4.91 & 0.8 & unk & & & \\
\hline 28.16 & 0.9 & hyd & 28.15 & 0.2 & unk & 28.04 & 2.0 & hyd & 28.05 & 0.3 & unk & & & \\
\hline \multirow[t]{2}{*}{30.55} & 0.3 & hyd & 30.54 & 1.2 & hyd & 30.42 & 0.8 & hyd & 33.13 & 0.2 & hyd & & & \\
\hline & & & 31.79 & 0.8 & hyd & & & & & & & & & \\
\hline \multicolumn{3}{|c|}{ Sample 5} & \multicolumn{3}{|c|}{ Sample 6} & \multicolumn{3}{|c|}{ Sample 7} & \multicolumn{3}{|c|}{ Sample 11} & \multicolumn{3}{|c|}{ Sample 12} \\
\hline 28.04 & 0.7 & unk & 4.98 & 1.8 & unk & 31.64 & 0.3 & hyd & 30.42 & 0.5 & hyd & 4.89 & 0.7 & unk \\
\hline \multirow[t]{2}{*}{31.64} & 0.2 & hyd & & & & & & & 31.64 & 0.3 & hyd & 30.42 & 1.1 & hyd \\
\hline & & & & & & & & & 33.71 & 0.2 & unk & & & \\
\hline \multicolumn{3}{|c|}{ Sample 19} & \multicolumn{3}{|c|}{ Sample 28} & \multicolumn{3}{|c|}{ Sample 29} & \multicolumn{3}{|c|}{ Sample 30} & & mple 31 & \\
\hline 25.34 & 0.7 & hyd & 30.14 & 0.7 & hyd & 27.93 & 0.4 & hyd & 27.44 & 0.3 & unk & 4.73 & 5.6 & unk \\
\hline 26.24 & 0.5 & unk & & & & 29.07 & 1.2 & hyd & 27.47 & 0.5 & unk & 27.44 & 0.4 & unk \\
\hline 26.88 & 1.2 & unk & & & & 29.58 & 0.5 & unk & 29.07 & 0.7 & hyd & & & \\
\hline & & & & & & 30.10 & 0.4 & hyd & & & & & & \\
\hline & & & & & & 30.15 & 0.5 & unk & & & & & & \\
\hline & & & & & & 31.26 & 0.4 & hyd & & & & & & \\
\hline & & & & & & 31.35 & 0.4 & hyd & & & & & & \\
\hline & mple 32 & & & mple 33 & & & mple 3 & & & mple 3 & & & mple 36 & \\
\hline 27.76 & 1.6 & unk & 27.75 & 0.5 & unk & 27.51 & 0.8 & unk & 27.47 & 0.6 & unk & 5.42 & 0.4 & hyd \\
\hline 29.07 & 1.0 & hyd & 29.07 & 1.0 & hyd & 27.55 & 1.2 & unk & 27.48 & 0.3 & unk & 27.75 & 0.5 & unk \\
\hline 29.58 & 0.5 & unk & 30.10 & 0.9 & hyd & 27.75 & 0.7 & unk & 27.75 & 0.4 & unk & 29.07 & 1.0 & hyd \\
\hline 30.11 & 1.0 & hyd & 31.26 & 0.7 & hyd & 29.08 & 1.0 & hyd & 29.07 & 0.6 & hyd & 29.58 & 0.7 & unk \\
\hline 31.27 & 0.8 & hyd & 33.61 & 0.4 & unk & 29.58 & 0.4 & unk & 29.59 & 0.4 & hyd & 30.11 & 0.7 & hyd \\
\hline & & & & & & 34.35 & 0.4 & hyd & & & & 31.26 & 0.7 & hyd \\
\hline & & & & & & & & & & & & 33.61 & 0.5 & hyd \\
\hline & nple 37 & & & mple 38 & & & mple 3 & & & mple 4 & & & mple 41 & \\
\hline 18.21 & 0.3 & hyd & 26.24 & 0.6 & unk & 10.62 & 0.5 & unk & 23.51 & 0.6 & hyd & 25.65 & 0.6 & unk \\
\hline 23.51 & 0.4 & hyd & 26.99 & 0.6 & hyd & 26.55 & 0.4 & unk & 25.14 & 0.4 & unk & 25.90 & 0.6 & unk \\
\hline 26.86 & 1.2 & unk & 28.12 & 1.3 & hyd & 26.78 & 6.9 & unk & 26.42 & 0.4 & hyd & 26.88 & 7.7 & unk \\
\hline 27.09 & 0.5 & hyd & 28.61 & 1.3 & hyd & 26.99 & 0.7 & hyd & 27.09 & 1.0 & hyd & 27.09 & 0.9 & hyd \\
\hline 28.23 & 1.1 & hyd & 29.13 & 1.0 & hyd & 28.12 & 2.5 & hyd & 28.22 & 2.1 & hyd & 28.23 & 3.4 & hyd \\
\hline 29.23 & 1.5 & hyd & 30.12 & 0.8 & hyd & 28.60 & 0.4 & unk & 28.96 & 0.4 & hyd & 28.96 & 0.7 & hyd \\
\hline 29.29 & 0.4 & hyd & & & & 28.86 & 0.4 & hyd & 29.23 & 1.4 & hyd & 29.23 & 2.2 & hyd \\
\hline 30.23 & 1.5 & hyd & & & & 29.13 & 1.4 & hyd & 29.28 & 0.5 & unk & 29.28 & 0.5 & unk \\
\hline 32.10 & 0.4 & hyd & & & & 29.85 & 0.4 & hyd & 29.97 & 0.5 & hyd & 29.97 & 0.9 & hyd \\
\hline & & & & & & 30.12 & 1.2 & hyd & 30.23 & 1.1 & hyd & 30.23 & 1.6 & hyd \\
\hline & & & & & & 30.96 & 0.4 & hyd & 31.10 & 0.5 & hyd & 31.09 & 0.7 & hyd \\
\hline & & & & & & & & & 32.10 & 0.4 & hyd & 32.10 & 0.6 & hyd \\
\hline & nple 42 & & & mple 43 & & & mple 4 & & & nple 4 & & & mple 46 & \\
\hline 23.51 & 0.5 & hyd & 17.04 & 0.5 & hyd & 25.90 & 2.9 & unk & 17.04 & 0.8 & hyd & 7.97 & 0.4 & unk \\
\hline 25.88 & 1.3 & unk & 25.90 & 3.5 & unk & 28.02 & 0.4 & hyd & 25.40 & 0.3 & unk & 27.74 & 0.4 & hyd \\
\hline 26.45 & 0.7 & hyd & 28.30 & 1.1 & hyd & 28.29 & 1.2 & hyd & 25.91 & 3.8 & unk & 28.87 & 0.9 & hyd \\
\hline 26.86 & 0.9 & unk & 29.25 & 0.9 & hyd & 28.46 & 0.5 & hyd & 27.75 & 0.4 & unk & 29.37 & 0.4 & unk \\
\hline 27.09 & 0.8 & hyd & & & & 29.01 & 0.6 & hyd & 28.30 & 1.1 & hyd & 29.61 & 0.4 & hyd \\
\hline 28.22 & 2.1 & hyd & & & & 29.25 & 1.5 & hyd & 29.02 & 0.5 & hyd & 29.88 & 0.4 & hyd \\
\hline 28.72 & 0.8 & unk & & & & 29.35 & 0.5 & unk & 29.26 & 1.3 & hyd & 30.69 & 0.5 & hyd \\
\hline 28.96 & 0.4 & hyd & & & & 30.19 & 0.4 & hyd & 30.19 & 0.5 & hyd & 31.94 & 0.5 & hyd \\
\hline 29.23 & 0.9 & hyd & & & & & & & & & & & & \\
\hline 29.28 & 0.7 & hyd & & & & & & & & & & & & \\
\hline 29.97 & 0.4 & hyd & & & & & & & & & & & & \\
\hline 30.23 & 0.8 & hyd & & & & & & & & & & & & \\
\hline 31.10 & 0.3 & hyd & & & & & & & & & & & & \\
\hline 32.16 & 0.4 & unk & & & & & & & & & & & & \\
\hline
\end{tabular}


TABLE 5 (Cont.)

\begin{tabular}{|c|c|c|c|c|c|c|c|c|c|c|c|c|c|c|}
\hline$R T^{b}$ & Conc $^{c}$ & $1 D^{d}$ & $R T^{b}$ & Conc $^{c}$ & $I D^{d}$ & $R T^{b}$ & Conc $^{c}$ & $10^{d}$ & $R T^{b}$ & Conc $^{c}$ & $\mathrm{ID}^{d}$ & $R T^{b}$ & Conc $^{c}$ & $I D^{d}$ \\
\hline \multicolumn{3}{|c|}{ Sample 47} & \multicolumn{3}{|c|}{ Sample 48} & \multicolumn{3}{|c|}{ Sample 49} & \multicolumn{3}{|c|}{ Sample 50} & \multicolumn{3}{|c|}{ Sample 51} \\
\hline 7.98 & 0.4 & unk & 7.98 & 0.4 & unk & 7.97 & 0.3 & unk & 27.55 & 0.6 & unk & 7.84 & 0.9 & unk \\
\hline 27.02 & 0.3 & unk & 27.56 & 0.6 & unk & 27.02 & 0.4 & unk & 27.74 & 0.6 & hyd & 27.43 & 0.3 & hyd \\
\hline 27.74 & 0.8 & hyd & 27.74 & 0.8 & hyd & 27.56 & 2.0 & unk & 27.92 & 0.4 & unk & 27.63 & 0.5 & hyd \\
\hline 28.87 & 2.3 & hyd & 28.87 & 2.7 & hyd & 27.74 & 0.7 & hyd & 27.93 & 0.6 & unk & 28.76 & 1.4 & hyd \\
\hline 29.37 & 0.8 & hyd & 29.37 & 0.4 & unk & 27.91 & 1.8 & unk & 27.94 & 0.3 & unk & 29.49 & 0.4 & hyd \\
\hline 29.60 & 0.8 & hyd & 29.60 & 1.0 & hyd & 27.92 & 0.9 & unk & 28.87 & 1.6 & hyd & 29.76 & 0.9 & hyd \\
\hline 29.87 & 1.2 & hyd & 29.88 & 2.4 & hyd & 28.01 & 0.5 & unk & 29.37 & 0.6 & hyd & 29.8 & 0.4 & unk \\
\hline 29.93 & 0.7 & hyd & 29.93 & 0.7 & hyd & 28.87 & 1.9 & hyd & 29.61 & 0.4 & hyd & 29.91 & 0.4 & hyd \\
\hline 30.03 & 0.5 & hyd & 30.03 & 1.0 & hyd & 29.38 & 0.8 & hyd & 29.88 & 0.6 & hyd & 30.55 & 0.6 & hyd \\
\hline 30.69 & 1.1 & hyd & 30.69 & 1.5 & hyd & 29.60 & 0.6 & hyd & 30.04 & 1.2 & hyd & 30.83 & 0.7 & hyd \\
\hline 30.97 & 0.8 & hyd & 30.97 & 1.5 & hyd & 29.88 & 1.1 & hyd & 30.69 & 0.6 & hyd & 30.94 & 0.3 & unk \\
\hline 31.08 & 0.6 & unk & 31.05 & 0.3 & hyd & 29.92 & 0.5 & hyd & 31.08 & 1.3 & unk & 31.78 & 0.5 & hyd \\
\hline 31.95 & 1.2 & hyd & 31.08 & 1.2 & unk & 30.04 & 0.4 & unk & 31.94 & 0.6 & hyd & 32.96 & 0.5 & hyd \\
\hline 32.38 & 0.4 & hyd & 31.95 & 1.6 & hyd & 30.69 & 0.9 & hyd & 32.30 & 0.5 & unk & & & \\
\hline 33.16 & 0.5 & hyd & 32.38 & 0.6 & hyd & 30.97 & 0.8 & hyd & 33.70 & 0.5 & unk & & & \\
\hline 33.50 & 0.4 & hyd & 32.49 & 0.4 & unk & 31.07 & 0.4 & unk & & & & & & \\
\hline \multirow[t]{2}{*}{33.71} & 2.3 & hyd & 33.16 & 0.6 & hyd & 31.95 & 0.9 & hyd & & & & & & \\
\hline & & & 33.50 & 0.5 & hyd & & & & & & & & & \\
\hline \multicolumn{3}{|c|}{ Sample 52} & \multicolumn{3}{|c|}{ Sample 53} & \multicolumn{3}{|c|}{ Sample 54} & \multicolumn{3}{|c|}{ Sample 55} & \multicolumn{3}{|c|}{ Sample 57} \\
\hline 27.54 & 2.4 & unk & 25.90 & 1.3 & unk & 25.90 & 1.1 & unk & 7.83 & 0.8 & unk & 27.34 & 2.1 & unk \\
\hline 27.71 & 0.6 & unk & 27.28 & 0.8 & hyd & 27.27 & 0.6 & unk & 27.43 & 0.6 & hyd & & & \\
\hline 28.85 & 1.4 & hyd & 27.30 & 0.5 & hyd & 27.33 & 0.7 & unk & 27.62 & 1.2 & hyd & & & \\
\hline 29.58 & 0.5 & hyd & 28.02 & 0.4 & hyd & 27.34 & 1.2 & unk & 28.75 & 2.9 & hyd & & & \\
\hline 29.86 & 0.7 & hyd & 28.30 & 1.5 & hyd & 28.30 & 0.6 & hyd & 29.48 & 0.5 & hyd & & & \\
\hline 29.90 & 0.4 & unk & 29.02 & 0.6 & hyd & 28.46 & 0.5 & hyd & 29.75 & 2.9 & hyd & & & \\
\hline 30.01 & 0.4 & hyd & 29.25 & 0.6 & hyd & 29.25 & 0.4 & hyd & 29.81 & 0.7 & hyd & & & \\
\hline 30.67 & 0.6 & hyd & 29.97 & & unk & 29.36 & 0.6 & unk & 29.90 & 0.6 & hyd & & & \\
\hline 30.95 & 0.5 & hyd & & & & 29.97 & 0.4 & hyd & 30.55 & 0.7 & hyd & & & \\
\hline 31.92 & 0.5 & unk & & & & & & & 30.82 & 2.2 & hyd & & & \\
\hline 33.67 & 0.5 & unk & & & & & & & 30.93 & 0.5 & unk & & & \\
\hline 33.68 & 0.3 & hyd & & & & & & & 31.77 & 1.0 & hyd & & & \\
\hline \multirow[t]{4}{*}{33.93} & 0.4 & unk & & & & & & & 32.07 & 0.5 & hyd & & & \\
\hline & & & & & & & & & 32.19 & 0.4 & hyd & & & \\
\hline & & & & & & & & & 32.30 & 0.6 & unk & & & \\
\hline & & & & & & & & & 32.95 & 0.6 & hyd & & & \\
\hline
\end{tabular}

a Samples not explicitly listed contained no compounds identified by the library search. The highest reported concentration for each identified compound is shown in boldface numerals.

b RT denotes the retention time in minutes.

c Conc denotes the approximate concentration in $\mathrm{mg} / \mathrm{kg}$ (parts per million).

d ID: unk denotes an unknown substance (mass-spectral quality less than $80 \%$ ); hyd denotes a hydrocarbon or hydrocarbon derivative. 
TABLE 6 Data Summary - TCLP Metals ${ }^{a, b}$

\begin{tabular}{|c|c|c|c|c|c|c|c|c|}
\hline \multirow[b]{3}{*}{ Sample } & \multicolumn{8}{|c|}{ Regulatory Limit (mg/L), by Metal } \\
\hline & Arsenic & Barium & Cadmium & Chromium & Mercury & Lead & Selenium & Silver \\
\hline & 5.0 & 100.0 & 1.0 & 5.0 & 0.2 & 5.0 & 1.0 & 5.0 \\
\hline 1 & & 0.96 & & & & & & \\
\hline 2 & & 0.92 & & & & & & \\
\hline 3 & & 0.79 & & & & & & \\
\hline 4 & & 1.30 & & & & & & \\
\hline 5 & & 1.50 & & & & & & \\
\hline 6 & & 0.52 & & & & & & \\
\hline 7 & & 0.58 & & & & & & \\
\hline 8 & & 1.10 & & & & & & \\
\hline 9 & & 0.72 & & & & & & 0.05 \\
\hline 10 & & 0.94 & & & & & & \\
\hline 11 & & 0.84 & & & & & & \\
\hline 12 & & 0.90 & & & & & & \\
\hline 13 & & 0.69 & & & 0.0008 & & & \\
\hline 14 & & 0.94 & & & & & & \\
\hline 15 & & 0.57 & & & & & & \\
\hline 16 & & 0.98 & & & 0.0005 & & & \\
\hline 17 & & 0.74 & & & 0.0006 & & & \\
\hline 18 & & 0.74 & & & 0.0006 & & & \\
\hline 19 & & 0.60 & & & & & & \\
\hline 20 & & 0.67 & & & & & & \\
\hline 21 & & 0.69 & & & & & & \\
\hline 22 & & 0.63 & & & 0.0005 & & & \\
\hline 23 & & 0.57 & & & & & & \\
\hline 24 & & 0.73 & & & & & & \\
\hline 25 & & 0.54 & & & & & & \\
\hline 26 & & 0.50 & & & & & & \\
\hline 27 & & 1.00 & & & & & & \\
\hline 28 & & 0.79 & & & & & & \\
\hline 29 & & 0.60 & & & & & & \\
\hline 30 & & 0.73 & & & & & & \\
\hline 31 & & 0.79 & & & & & & \\
\hline 32 & & 0.51 & & & & & & \\
\hline 33 & & 0.51 & & & & & & \\
\hline 34 & & 0.70 & & & & & & \\
\hline 35 & & 0.90 & & & & & & \\
\hline 36 & & 1.20 & & & & & & \\
\hline 37 & & 0.40 & & & & & 0.28 & \\
\hline 38 & & 0.27 & & & & & 0.31 & \\
\hline 39 & & 0.34 & & & & & & \\
\hline 40 & & 0.26 & 0.05 & 0.19 & & & 0.27 & \\
\hline 41 & & 0.07 & & & & & & \\
\hline 42 & & 0.45 & & & & & & \\
\hline 43 & & 0.56 & & & & & & \\
\hline 44 & & 0.63 & & & & & 0.28 & \\
\hline 45 & & 0.79 & & & & & & \\
\hline 46 & & 1.40 & & & & & & \\
\hline 47 & & 1.20 & & & & & & \\
\hline
\end{tabular}




\begin{tabular}{|c|c|c|c|c|c|c|c|c|}
\hline \multirow[b]{3}{*}{ Sample } & \multicolumn{8}{|c|}{ Regulatory Limit (mg/L), by Metal } \\
\hline & Arsenic & Barium & Cadmium & Chromium & Mercury & Lead & Selenium & Silver \\
\hline & 5.0 & 100.0 & 1.0 & 5.0 & 0.2 & 5.0 & 1.0 & 5.0 \\
\hline 48 & & 0.99 & & & & & & \\
\hline 49 & & 0.95 & & & & & & \\
\hline 50 & & 0.92 & & & & & & \\
\hline 51 & & 0.98 & & & & & & \\
\hline 52 & & 0.88 & & & & & & \\
\hline 53 & & 0.68 & & & & & & \\
\hline 54 & & 0.65 & & & & & 0.25 & \\
\hline 55 & & 1.30 & & & & & & \\
\hline 56 & & 1.10 & & & & & & \\
\hline 57 & & 0.77 & & & & & & \\
\hline
\end{tabular}

a Values given in $\mathrm{mg} / \mathrm{L}$.

b Blank entries denote nondetection.

\subsection{Soil Composition Data}

Table 7 summarizes the results of all other analyses performed in addition to those already discussed. These analytes may be called soil composition parameters.

With respect to the metals data, sample 8 had the highest aluminum, calcium, magnesium, manganese, potassium, and sodium values of any sample and is clearly anomalous compared with the other samples. The reason for this is not known. The only levels noticeably outside APG regional norms were the calcium and magnesium levels in sample 8 . The calcium level is $3.6 \%$, compared with a typical range of $0.08 \%-1.2 \%$, and the magnesium level was $1.3 \%$, compared with a typical range of $0.05 \%-0.7 \%$.

The "metals" results apparently represent total metals. In samples $1-12$, the estimated total level of metal oxides was reported instead of total metals.

The "silicates" heading is misleading, because the value reported by the analytical laboratory as "silicates" is obtained by subtracting the total metals, total organics (presumably obtained by summing up all the organics specifically included on the analyte lists of the various methods), and moisture from $100 \%$. This result does not therefore involve any substances that may be present in soil but were not determined, such as total organic matter. In samples 24-36, moisture was not determined, and the "silicates" result is above $96 \%$ in all cases. 
TABLE 7 Data Summary - Soil Composition ${ }^{a}$

\begin{tabular}{|c|c|c|c|c|c|c|c|c|c|c|c|c|c|c|}
\hline \multirow[b]{3}{*}{ Sample } & \multicolumn{10}{|c|}{ Method } & \multirow[b]{3}{*}{ Metals } & \multirow[b]{3}{*}{ Organics } & \multirow[b]{3}{*}{ Moisture } & \multirow[b]{3}{*}{ Silicates $^{c}$} \\
\hline & 6010 & 6010 & 6010 & 6010 & 6010 & 6010 & 6010 & 6010 & 6010 & $2540 G$ & & & & \\
\hline & Aluminum & Calcium & Iron & Magnesium & Manganese & Phosphorus & Potassium & Sodium & Titanium & Solids & & & & \\
\hline 1 & 0.63 & 0.054 & 1.5 & 0.120 & --- & 0.016 & 0.041 & $\cdots$ & $\cdots$ & 82 & $6^{b}$ & $<1$ & 18 & 75 \\
\hline 2 & 0.68 & 0.034 & 2.2 & 0.150 & 0.086 & 0.020 & 0.035 & $\ldots$ & $\cdots$ & 80 & $8^{b}$ & $<1$ & 20 & 71 \\
\hline 3 & 0.67 & 0.031 & 1.5 & 0.120 & 0.011 & 0.018 & 0.037 & $\ldots$ & $\cdots$ & 80 & $6^{b}$ & $<1$ & 20 & 73 \\
\hline 4 & 0.39 & 0.069 & 1.1 & 0.096 & $\ldots$ & 0.010 & 0.031 & -..- & $\cdots$ & 80 & $4^{b}$ & $<1$ & 20 & 75 \\
\hline 5 & 0.39 & 0.098 & 1.3 & 0.088 & $-\cdots$ & 0.013 & 0.023 & --- & $\ldots$ & 84 & $5^{b}$ & $<1$ & 16 & 78 \\
\hline 6 & 0.46 & 0.110 & 1.2 & 0.770 & 0.013 & 0.011 & 0.043 & $\ldots$ & $\ldots-$ & 89 & $6^{b}$ & $<1$ & 11 & 83 \\
\hline 7 & 0.37 & 0.050 & 1.1 & 0.120 & $\ldots$ & 0.010 & 0.024 & $\cdots$ & $\ldots$. & 85 & $4^{b}$ & $<1$ & 15 & 80 \\
\hline 8 & 1.00 & 3.600 & 1.4 & 1.300 & 0.150 & 0.012 & 0.140 & 0.092 & $\cdots$ & 85 & $19^{b}$ & $<1$ & 15 & 66 \\
\hline 9 & 0.51 & 0.190 & 1.3 & 0.180 & 0.010 & 0.012 & 0.043 & 0.014 & $\cdots$ & 84 & $6^{\mathrm{b}}$ & $<1$ & 16 & 77 \\
\hline 10 & 0.74 & 0.042 & 1.7 & 0.021 &.-- & 0.016 & 0.057 & 0.011 & .... & 84 & $7^{b}$ & $<1$ & 16 & 77 \\
\hline 11 & 0.61 & 0.074 & 1.4 & 0.130 & 0.011 & 0.014 & 0.045 & $\cdots$ & .... & 78 & $6^{b}$ & $<1$ & 22 & 71 \\
\hline 12 & 0.54 & 0.029 & 1.4 & 0.140 &.-- & 0.013 & 0.052 & $\ldots$ & $\ldots$. & 74 & $6^{b}$ & $<1$ & 26 & 67 \\
\hline 13 & 0.74 & 0.029 & 1.9 & 0.180 & $\ldots$ & 0.014 & 0.100 & 0.020 & --- & 80.6 & 3.0 & $<0.01$ & 19.4 & 77.6 \\
\hline 14 & 0.64 & 0.061 & 1.5 & 0.093 & 0.013 & 0.018 & 0.087 & 0.015 & $\ldots$ & 71.9 & 2.5 & $<0.01$ & 28.1 & 69.4 \\
\hline 15 & 0.61 & 0.075 & 1.2 & 0.110 & $\ldots$ & 0.014 & 0.084 & 0.014 & $-\cdots$ & 76.5 & 2.1 & $<0.01$ & 23.5 & 74.4 \\
\hline 16 & 0.46 & 0.460 & 1.1 & 0.220 & 0.024 & 0.013 & 0.092 & 0.013 & $\cdots$ & 80.0 & 2.4 & $<0.01$ & 20.0 & 77.6 \\
\hline 17 & 0.54 & 0.130 & 1.4 & 0.180 & 0.011 & 0.016 & 0.087 & 0.015 & $\cdots$ & 87.2 & 2.4 & $<0.01$ & 12.8 & 84.8 \\
\hline 18 & 0.52 & 0.038 & 1.4 & 0.160 & ...- & 0.010 & 0.090 & 0.015 & $\cdots$ & 81.2 & 2.2 & $<0.01$ & 18.8 & 79.0 \\
\hline 19 & 0.49 & 0.110 & 1.2 & 0.260 & 0.010 & 0.012 & 0.093 & 0.014 & $\ldots .-$ & 81.8 & 2.2 & $<0.01$ & 18.2 & 79.6 \\
\hline 20 & 0.61 & 0.130 & 1.2 & 0.210 & 0.011 & 0.016 & 0.110 & 0.014 & $\cdots$ & 87.2 & 3.1 & $<0.01$ & 12.8 & 84.1 \\
\hline 21 & 0.57 & 0.200 & 1.3 & 0.170 & -..- & 0.013 & 0.089 & 0.015 & $\cdots-$ & 85.0 & 2.4 & $<0.01$ & 15.0 & 82.6 \\
\hline 22 & 0.51 & 0.110 & 1.2 & 1.000 & 0.010 & 0.010 & 0.100 & 0.014 & $\cdots$ & 86.2 & 3.0 & $<0.01$ & 13.8 & 83.2 \\
\hline 23 & 0.45 & 0.460 & 0.93 & 0.430 & 0.020 & 0.011 & 0.087 & 0.012 & $\cdots$ & 80.3 & 2.4 & $<0.01$ & 19.7 & 77.9 \\
\hline 24 & 0.647 & 0.425 & 1.14 & 0.313 & 0.020 & -.. & 0.069 & -... & $\cdots$ & 81 & 2.6 & $<0.01$ & .... & 97.4 \\
\hline 25 & 0.699 & 0.554 & 1.44 & 0.340 & 0.030 & --- & 0.076 & $\ldots$ & $\cdots$ & 82 & 3.2 & $<0.01$ & $\ldots$ & 96.8 \\
\hline 26 & 0.536 & 0.080 & 1.10 & 0.134 & --- & ...- & 0.055 & $\cdots$ & .... & 84 & 1.9 & $<0.01$ & $\ldots$ & 98.1 \\
\hline 27 & 0.815 & 0.122 & 1.46 & 0.162 & $\ldots .$. & --- & 0.087 & $\cdots$ & $\cdots$ & 79 & 2.6 & $<0.01$ & $\ldots$ & 97.4 \\
\hline 28 & 0.547 & 0.060 & 1.74 & 0.127 & 0.020 & $\ldots$ & 0.063 & $\ldots$ & $\cdots$ & 86 & 2.6 & $<0.01$ & -... & 97.4 \\
\hline 29 & 0.414 & 0.030 & 0.71 & 0.080 & $-\cdots$ & --- & 0.040 & .... & $\cdots$ & 81 & 1.3 & $<0.01$ & $\ldots$ & 98.7 \\
\hline
\end{tabular}


TABLE 7 (Cont.)

\begin{tabular}{|c|c|c|c|c|c|c|c|c|c|c|c|c|c|c|}
\hline \multirow[b]{3}{*}{ Sample } & \multicolumn{10}{|c|}{ Method } & \multirow[b]{3}{*}{ Metals } & \multirow[b]{3}{*}{ Organics } & \multirow[b]{3}{*}{ Moisture } & \multirow[b]{3}{*}{ Silicates $^{c}$} \\
\hline & 6010 & 6010 & 6010 & 6010 & 6010 & 6010 & 6010 & 6010 & 6010 & $2540 \mathrm{G}$ & & & & \\
\hline & Aluminum & Calcium & Iron & Magnesium & Manganese & Phosphorus & Potassium & Sodium & Titanium & Solids & & & & \\
\hline 30 & 0.678 & 0.027 & 1.29 & 0.094 & $\ldots$ & .... & 0.058 & .... & $\cdots$ & 80 & 2.2 & $<0.01$ & $\ldots$ & 97.8 \\
\hline 31 & 0.541 & 0.188 & 1.44 & 0.227 & 0.011 & $\cdots$ & 0.067 & $-\cdots$ & $\cdots$ & 86 & 2.5 & $<0.01$ & $\cdots$ & 97.5 \\
\hline 32 & 0.548 & -... & 1.05 & 0.098 & -..- & $\cdots$ & 0.066 & $\cdots$ & $\ldots$. & 79 & 1.8 & $<0.01$ & $\cdots$ & 98.2 \\
\hline 33 & 0.499 & 0.241 & 0.679 & 0.156 & 0.015 & $\cdots$ & 0.061 & --- & --- & 78 & 1.7 & $<0.01$ & .... & 98.3 \\
\hline 34 & 0.567 & -.-- & 0.759 & 0.063 & -... & $\cdots$ & 0.054 & $\ldots$ & $\cdots$ & 77 & 1.4 & $<0.01$ & --- & 98.6 \\
\hline 35 & 0.720 & $\ldots$ & 1.040 & 0.147 & $\cdots$ & $\ldots$ & 0.092 & -... & --- & 77 & 2.0 & $<0.01$ & --- & 98.0 \\
\hline 36 & 0.683 & --- & 1.030 & 0.170 & $\ldots$ & $\ldots$ & 0.080 & --- & $\cdots$ & 76 & 2.0 & $<0.01$ & $\cdots$ & 98.0 \\
\hline 37 & 0.245 & 0.057 & 0.640 & 0.080 & --- & -..- & 0.029 & $\ldots$ & $\cdots$ & 83 & 1.05 & $<0.01$ & 17 & 81.9 \\
\hline 38 & 0.317 & -... & 0.401 & 0.071 & --- & -.-- & 0.030 & $\ldots$ & $\ldots$ & 81 & 0.82 & $<0.01$ & 19 & 80.2 \\
\hline 39 & 0.301 & -... & 0.402 & 0.064 & -..- & $\ldots$ & 0.031 & $\cdots$ & $\cdots$ & 80 & 0.80 & $<0.01$ & 20 & 79.2 \\
\hline 40 & 0.281 & $\cdots$ & 0.539 & 0.052 & $\ldots$ & $\ldots$ & 0.031 &.-- & -..- & 81 & 0.90 & $<0.01$ & 19 & 80.1 \\
\hline 41 & 0.280 & $\cdots$ & 0.374 & 0.054 & $\cdots$ & -..- & 0.037 & $\cdots$ & $\cdots$ & 80 & 0.74 & $<0.01$ & 20 & 79.3 \\
\hline 42 & 0.208 & 0.047 & 0.315 & 0.038 & $\cdots$ & $\cdots$ & 0.014 & -... & $\cdots$ & 80 & 0.62 & $<0.01$ & 20 & 79.4 \\
\hline 43 & 0.188 & 0.012 & 0.447 & 0.027 & $\cdots$ & $-\cdots$ & 0.024 & $\cdots$ & .... & 84 & 0.71 & $<0.01$ & 16 & 83.3 \\
\hline 44 & 0.217 & $\cdots$ & 0.556 & 0.003 & $\cdots$ & --- & 0.022 & $\cdots$ & $\cdots$ & 85 & 0.84 & $<0.01$ & 15 & 84.2 \\
\hline 45 & 0.322 & 0.010 & 0.669 & 0.044 & $-\cdots$ & --- & 0.029 & --.- & ---- & 85 & 1.08 & $<0.01$ & 15 & 83.9 \\
\hline 46 & 0.811 & .... & 1.47 & 0.163 & $\cdots$ & $\cdots$ & 0.052 & 0.010 & 0.012 & 92 & 1.40 & $<0.01$ & 8 & 90.6 \\
\hline 47 & 0.708 & 0.021 & 1.25 & 0.116 & $-\cdots$ & -..- & 0.040 & -..- & -..- & 94 & 2.10 & $<0.01$ & 6 & 91.9 \\
\hline 48 & 0.860 & ---- & 1.87 & 0.195 & $\cdots$ & $\cdots$ & 0.043 & 0.012 & 0.013 & 90 & 3.00 & $<0.01$ & 10 & 87.0 \\
\hline 49 & 0.842 & $\cdots$ & 1.84 & 0.185 & $\ldots$ & ...- & 0.045 & 0.016 & 0.010 & 89 & 2.90 & $<0.01$ & 11 & 86.1 \\
\hline 50 & 0.696 & $\cdots$ & 1.26 & 0.105 & --- & --- & 0.038 & -..- & -..- & 93 & --.- & $<0.01$ & .... & $\ldots$ \\
\hline 51 & 0.682 & ---- & 1.34 & 0.118 & -..- & ---- & 0.037 & $\ldots$ & .... & 93 & 2.20 & $<0.01$ & 7 & 90.8 \\
\hline 52 & 0.712 & 0.010 & 1.61 & 0.139 & $\ldots$ & .... & 0.045 & 0.013 & $\ldots$. & 91 & 2.50 & $<0.01$ & 9 & 88.5 \\
\hline 53 & 0.236 & -..- & 0.450 & 0.029 & $\cdots$ & ...- & 0.021 & $---\cdot$ & $\cdots$ & 85 & 0.74 & $<0.01$ & 15 & 84.3 \\
\hline 54 & 0.218 & $\cdots$ & 0.434 & 0.032 & $\cdots$ & ...- & 0.022 & ---- & .... & 83 & 0.71 & $<0.01$ & 17 & 82.3 \\
\hline 55 & 0.523 & --- & 0.719 & 0.069 & ....- & .... & -..- & $\cdots$ & .... & 86 & 1.30 & $<0.01$ & 14 & 84.7 \\
\hline 56 & -..- & $\ldots$ & $\cdots$ & -..- & $\cdots$ & $\cdots--$ & $\cdots$ & $-\cdots$ & -..- & -.- & $\ldots$ & $<0.01$ &..- & $\ldots$ \\
\hline 57 & 0.313 & 0.023 & 0.799 & 0.051 & -... & --.- & 0.031 & -..- & $\cdots$ & 87 & 1.20 & $<0.01$ & 13 & 85.8 \\
\hline
\end{tabular}

a Values given in percent.

- Values reported as metal oxides.

c Obtained by subtracting metals, organics, and moisture percentages from $100 \%$. 


\section{Summary of Findings}

Table 8 summarizes the highest concentrations found for each analyte identified in any of the 57 composite samples taken at the site of the proposed agent disposal facility. The findings of this review are summarized below.

\subsection{Analytical Method Suitability}

All analytical methods used for the composite samples of interest here are suitable for use, except Method 9020A (Total Organic Halides), which is intended for an aqueous solution matrix, and Method 418.1 (Total Petroleum Hydrocarbons). The suitability of Method 418.1 is

TABLE 8 Highest Concentrations of Identified Organic Contaminants

\begin{tabular}{|c|c|c|c|}
\hline Substance & $\begin{array}{c}\text { Maximum } \\
\text { Concentration }\end{array}$ & $\begin{array}{c}\text { Sample } \\
\text { Number(s) }\end{array}$ & Analytical Method \\
\hline Di-n-butyl phthalate & $2,000 \mu \mathrm{g} / \mathrm{kg}$ & 18,21 & SVOA; 8270 \\
\hline Diethyl phthalate & $3,200 \mu \mathrm{g} / \mathrm{kg}$ & 19 & SVOA; 8270 \\
\hline Benzyl butyl phthalate & $660 \mu \mathrm{g} / \mathrm{kg}$ & 19 & SVOA; 8270 \\
\hline Cyclotetracosane ${ }^{a}$ & $3.4 \mathrm{mg} / \mathrm{kg}$ & 41 & SVOA; 8270 \\
\hline 1,1,2,2-tetrachloroethane & $1,100 \mu \mathrm{g} / \mathrm{kg}$ & 15 & VOA; 8260 \\
\hline Octamethyl-cyclotetrasiloxane & $367 \mu \mathrm{g} / \mathrm{kg}$ & 51 & VOA; 8260 \\
\hline Trichloroethylene & $110 \mu \mathrm{g} / \mathrm{kg}$ & 20 & VOA; 8260 \\
\hline Tetrachloroethylene & $23 \mu \mathrm{g} / \mathrm{kg}$ & 23 & VOA; 8260 \\
\hline Tridecane $^{b}$ & $11 \mu \mathrm{g} / \mathrm{kg}$ & 6 & VOA; 8260 \\
\hline Methylene chloride & $10 \mu \mathrm{g} / \mathrm{kg}$ & 54 & VOA; 8260 \\
\hline Trichlorofluoromethane & $9.1 \mu \mathrm{g} / \mathrm{kg}$ & 55 & VOA; 8260 \\
\hline Hexamethyl-cyclotrisiloxane ${ }^{b}$ & $9 \mu \mathrm{g} / \mathrm{kg}$ & 52 & VOA; 8260 \\
\hline Toluene & $6.5 \mu \mathrm{g} / \mathrm{kg}$ & 51 & VOA; 8260 \\
\hline Total organic halides & $25 \mathrm{mg} / \mathrm{kg}$ & 13 & TOX; 9020 \\
\hline $4,4^{\prime}-\mathrm{DDE}$ & $25.4 \mu \mathrm{g} / \mathrm{kg}$ & 55 & PCB/pesticides; 8081 \\
\hline $4,4^{\prime}-\mathrm{DDT}$ & $21.5 \mu \mathrm{g} / \mathrm{kg}$ & 48 & PCB/pesticides; 8081 \\
\hline Total "petroleum" hydrocarbons & $64 \mathrm{mg} / \mathrm{kg}$ & 38 & TPH; 418.1 \\
\hline
\end{tabular}

a Identified during SVOA mass-spectral library search; not on Method 8270 analyte list.

b Identified during VOA mass-spectral library search; not on Method 8260 analyte list. 
questionable because of its lack of specificity to petroleum hydrocarbons. Method 8021 (BTEX) is suitable, but redundant, because the same analytes were analyzed to greater sensitivity by other methods already in use.

\subsection{Quality Assurance/Quality Control}

The quality of the analytical data is considered adequate for their intended use.

\subsection{Semivolatile Organics (SVOA)}

As discussed in Section 4, it is unlikely that phthalate contamination is as widespread at the site as is indicated by the analytical results. The possibility of phthalate contamination is limited to the area covered by composite samples 13-23, which are associated with the CDB building in Figure 1. However, because phthalates were not detected in other samples from this area (numbers $24,25,26$, and 57 ), it is also possible that all the apparent phthalate contamination is a laboratory artifact.

The high-molecular-weight hydrocarbons identified in the SVOA mass-spectral library search are more consistent with known natural sources of such substances than with a petroleum product source. All identified hydrocarbons are known natural products, and no evidence exists for the complex mixture of hydrocarbons characteristic of petroleum fuels.

\subsection{Volatile Organics (VOA)}

The VOA analytes toluene, methylene chloride, and trichlorofluoromethane are probably not associated with site contamination, but rather with laboratory cross-contamination. However, the presence of the chlorinated hydrocarbons 1,1,2,2-tetrachloroethane, trichloroethylene, and tetrachloroethylene was confirmed independently and in all likelihood represents residual site contamination due to past activities.

The VOA mass-spectral library search identified tridecane and two siloxane derivatives. These are very likely of natural origin and GC column degradation, respectively.

\subsection{Total Petroleum Hydrocarbons (TPH)}

The TPH results obtained by using Method 418.1 are almost certainly due to naturally occurring hydrocarbons rather than to widespread petroleum hydrocarbon contamination. This finding is based on the lack of specificity of Method 418.1, the conflicting results from samples 
tested by using both Method 418.1 and Method 8015 (Modified), the lack of any indication of petroleum hydrocarbons in a large set of independent related analyses, and the identification of several hydrocarbons known to be associated with vegetation.

The area covered by the CDB building (see Figure 1) was found to have generally higher levels of organic contamination than other areas and could also contain traces of petroleum hydrocarbon contamination associated with past activities.

\subsection{Pesticides}

Pesticides were detected in low part-per-billion levels in a localized wooded area at the northern edge of the site. These substances may be present as a result of past weed control in this area. Analyses for pesticides were not carried out for all composite samples.

\subsection{Total Organic Halides}

The "single-number" Total Organic Halides data are of questionable value because they were obtained from an inappropriate matrix and do not provide any compound-specific information about possible soil contamination.

\subsection{TCLP}

The TCLP procedure produces an aqueous leachate solution, which is then subjected to specified analyses for the substances of interest. Only the levels of several heavy metals were above quantitation limits; no organic substance was found above quantitation limits in the TCLP leachate. The found levels of all analytes checked were well below the associated regulatory limits.

\subsection{Soil Composition}

The soil composition data all lie within normal limits, except for slightly elevated levels of calcium and magnesium in one sample. 


\section{References}

U.S. Environmental Protection Agency, 1986, Test Methods for Evaluating Solid Waste, 3rd Edition, U.S. EPA Office of Solid Waste Report SW-846, Washington, D.C.

American Public Health Association, 1992, Standard Methods for the Examination of Water and Wastewater, 18th Edition, APHA, Washington, D.C.

Dragun, J., and J. Barkach, 1989, "Three Common Misconceptions Concerning the Fate and Cleanup of Petroleum Products in Soil and Groundwater," Chapter 14 in Petroleum in Contaminated Soils, E.J. Calabrese and P.T. Kostecki (editors), Vol. 2, Lewis Publishers, Chelsea, Mich.

Gustafson, J.B., "Using TPH in Risk-Based Corrective Action," Shell Development Company, U.S. EPA Internet document [http://www.epa.gov/swerust 1/rbdm/tphrbca.htm]. 